\title{
1. Introduction. Global governance and democracy: invitation to a multidisciplinary dialogue
}

\section{Emilie Bécault, Matthias Lievens, Jan Wouters and Antoon Braeckman}

Since it was first introduced two decades ago by the writings of James Rosenau and the 'Commission for Global governance' (Rosenau and Czempiel 1992; Commission on Global Governance 1995), global governance has become a central topic of inquiry for a myriad of political scientists, legal scholars, economists and political philosophers. Spurred by a number of key global developments including the end of the Cold War, the skills revolution, economic globalization and the growing awareness of the dangers posed by some transnational problems, the concept of global governance has emerged as a useful analytical and normative tool for making sense of profound shifts sweeping the international political landscape (Weiss 2000, 796; Barnett and Sikkink 2008, 78; Kersbergen and Waarden 2004, 143). Chief among these shifts is the notion that states should, and can, no longer be regarded as the sole source of regulation at the global level. Increasingly, a wide range of actors - from individuals to local communities, to businesses, non-governmental organizations (NGOs) and international organizations - are engaged in numerous governingrelated activities, structuring and directing the behaviour of interdependent actors and resulting in some relatively novel modes of governance such as public-private partnerships, coalitions of subnational governments, informal groups of like-minded government officials, and private regulatory schemes. But, notwithstanding two decades of vibrant scholarship that spread over numerous literatures and disciplines, one can still observe several unresolved issues with regard to the study of global governance and especially with respect to its implications for thinking about democratic legitimacy.

First and from a conceptual perspective, it is clear that 'global governance' still remains an elusive term. Subject to an evolving, extremely diverse body of research, it has ever since its emergence struggled with 
concerns best embodied in Finkelstein's original critique of the concept (Finkelstein 1995, 368): 'global governance appears to be virtually anything'. Scholars regularly point to several key dimensions that set global governance apart from international relations in the traditional meaning of the term, pointing to the multi-level, multi-actor and polycentric nature of emerging governing processes and the transformations of authority they bring with it (Dingwerth and Pattberg 2006), but the meanings of the two terms 'global' and 'governance' often remain ambiguous. In addition, the concept of global governance has been subject to such a vast array of empirical applications across many disciplines that they tend to obscure rather than clarify what its empirical added value is compared to more traditional notions of international coordination and cooperation. Thus far, what emerges from the scholarship is a complex and enormously diverse picture of the global governance phenomenon, testifying above all to the fact that global governance might ultimately have many connotations and mean different things to different people. Relatedly, we have yet to achieve a deeper and more comprehensive understanding of how governance as an empirical phenomenon actually varies across and between issue areas of world politics. One main reason for this gap in the literature is that little communication or interaction takes place between disciplines whose respective take on the global governance phenomenon too often proceeds within rigid ontological and epistemological commitments. Political science and the subdiscipline of international relations, in particular, have long been studying the phenomenon of global governance, but largely in isolation from other neighbouring disciplines, such as law, economics, geography, sociology and even history, in which the concept has also found its way, albeit in more recent years. A similar problem can be observed in regard to the issue areas of world politics, with studies of specific domains of global governance, such as human rights, environmental protection and international security, rarely engaging with work conducted in other fields. Methodological issues aside, conceptual efforts seeking to acknowledge rather than shun the diversity and complexity of global governance would greatly benefit from research orientations that more explicitly bring together insights taken from distinct disciplines and issue areas of global politics.

A second topic also very much in need of cross-disciplinary interaction has to do with the legitimacy of global governance, especially its democratic credentials. What is clear thus far is that governance beyond the state is rapidly expanding and has significant consequences: decision-making, both formal and informal, is more than ever taking place beyond the nation-state, and its increasingly important (domestic) impact is frequently beyond the control of democratically elected nation-state governments 
and legislatures (Pauwelyn et al. 2012). With global governance developing as a central theme of academic inquiry, a lively debate has emerged in recent years about the potential normative and empirical underpinnings of a more democratic international order, bringing to bear crucial questions regarding the democratic potentials and limitations of specific global governance mechanisms. Addressing these questions, however, has been far from straightforward. As a relatively novel approach to making and thinking about global politics, global governance challenges long-standing ideas about democracy worked out within the confines of the territorially bounded nation-state. An enormous share of the conceptual arsenal which political theorists, scientists and philosophers have at their disposal to think about democracy is based on our experience within domestic settings. This implies that almost all existing concepts to think about democracy - such as representation, (popular) sovereignty, the people, citizenship, constituent power, the demos, rights, public opinion and the difference between public and private - are strongly embedded within that experience, which is grounded in a particular global configuration of political entities, namely states. For theorists of global democracy, then, an initial and still current task has been to re-envision conventional (state-centric) democratic ideals and practices in ways that make them better suited to a post-national context, characterized notably by the absence of some overarching authority, the loss of clear territorial boundaries, and the lack of some coherently defined demos. In the course of this endeavour, radical, cosmopolitan and procedural democratic models have been promoted as potential solutions to global democratic deficits. With regard to the democratic legitimacy of specific global governance arrangements or architectures, the emerging scholarship tends to be divided into two distinct areas of enquiry that have little interaction with one another. There is, on the one hand, a rapidly growing global governance literature, firmly grounded in an empirical approach that tends to focus on conceptions of legitimacy framed in terms of effectiveness or acceptance and recognition by relevant audiences or stakeholders. While scholars working within this line of research offer valuable insights regarding the institutional design and functioning of existing global governance arrangements, they tend not to relate their empirical findings to normative discussions of democratic legitimacy. On the other hand, there is political theory literature, which, conversely, has been mainly concerned with developing normative criteria, guidelines and models against which to evaluate or enhance the democratic legitimacy of global governance. The problem is that these normative discussions are often formulated with almost no concern for what is actually taking place on the ground, thereby risking losing their guiding value. As Brassett et al. $(2012,369)$ suggest while reflecting on the normative-practice split in the 
emerging scholarship on global private governance, '[a] marked tendency in the analytical political theory literature is that, rather than addressing the normative legitimacy of existing governance practices, authors tend to articulate "ideal theoretic" proposals that best exemplify their own normative position'. If research that brings together normative and empirical modes of theorizing is often difficult to conduct, the goal of developing deeper normative-empirical dialogues should be given more importance, as both normative and empirical approaches to global democracy and global governance can learn a lot from each other's progress.

With this in mind, the main purpose of this edited volume is to attempt to fill this twofold gap in the ongoing debates on global governance and its democratic legitimacy. To that end, it brings together the analytical perspectives of four disciplines that naturally touch upon the relationship between global governance and democracy: political theory, international relations, international political economy and international law. It also covers four major issue areas of contemporary global governance: human rights, peace and security, global environmental protection and global economy. One of the volume's central contributions is that it paves the way for a more informed dialogue between disciplines and between normative and empirical approaches. At its core, indeed, lies the contention that the interaction between theoretical and empirical research is crucial. Empirical analyses of selected cases within key areas of global governance nurture philosophical theorizing, and vice versa; theoretical analysis informs and directs empirical research with regard to the decisive features and principles of democracy that should be subjected to empirical scrutiny.

This volume finds its origins in an initial phase of a seven-year research programme (2010-2017) on Global Governance and Democratic Government. This programme, conducted jointly between the Leuven Centre for Global Governance Studies and the Centre for Ethics, Social, and Political Philosophy of the University of Leuven (KU Leuven), Belgium, builds upon an intensive cooperation and unique crossfertilization between various disciplines: international and European law, international relations, political economy and political philosophy. In its initial phase, the programme's goal is to assess the architecture, practices and processes of global governance from a democratic theory perspective. Given the object and focus of the programme, the interaction between theoretical and empirical research is crucial.

The present volume proceeds in two steps, linking a critical assessment of the current research on global democracy and governance (Parts I and II) with a set of innovative ideas on how to advance research within, but also across, the disciplines concerned (Parts III and IV). Specifically, in Part I, the topic of global governance and democratic legitimacy is tackled from 
a political philosophy perspective. Part II provides a set of four studies of the different global governance domains that lie at the heart of the project: climate change, economic, human rights and security governance. They provide insights into what global governance can and does mean in major policy fields, and identify the relevant debates about it in terms of democratic legitimacy. Additional focus is provided by the choice of a particular case study within each of the broader fields. In Part III, two contributions pave the way for a more informed dialogue between disciplines. In Part IV, a concluding chapter sets the agenda for future research and closes with a set of reflections on emerging themes and blind spots.

\section{PART I: GLOBAL GOVERNANCE AND ITS DEMOCRATIC LEGITIMACY}

Chapters 2 and 3 take a political theory approach to the discussion of global governance and its democratic legitimacy. They address two crucial theoretical questions associated with the rapidly growing expansion of governance beyond the state: what is global governance? (that is, where does it come from, and how can it be conceptually grasped?), and can and should it be democratized?

In Chapter 2, 'Can we democratize global governance? Two guiding scenarios based on a narrative approach', Alessandro Mulieri aims to clarify the question of the democratization of global governance, analysing the two historical and political narratives that form global governance: that of 'global' and that of 'governance'. In proposing what he calls a narrative approach to theorizing about global governance, Mulieri suggests that the relationship between government and governance is the central theme for the democratization of global governance. Based on the concept of political authority and a reflection on the scope of agency at the global level, he proposes two guiding scenarios for democratic global governance. In the first scenario, in which government prevails over governance, democratic theory can adopt standard theories of representation, double models of international and external accountability, and community-based ideas of equality. In the second scenario, in which governance prevails over government, democratic theory can focus on constructivist models of representation, vertical and horizontal theories of accountability, and ideals of equality based on all-affectedness and inspired by democracy models in the transnational arena.

In Chapter 3, entitled 'The value of the ideal of democracy in global governance', Haye Hazenberg puts forward four proposals that recognizably instantiate the value of democracy in global governance. Democracy, 
or the idea that people rule collectively, can be elaborated through a social justice standard that accords power proportionally, or through a political standard that takes numerical equality and a non-political basis as central. Institutionally, global democracy can be thought of to consist either in an association of democratic states or in global democratic institutions that go over and beyond state structures. By combining these four ideas, the author builds four proposals for democratizing global governance: the first is a social association of states, or the United Nations (UN) system; the second is a social global democracy, or global governance; the third is political global democracy, or a world state; and the fourth is a political association of states, or global civics.

\section{PART II: GLOBAL GOVERNANCE AND DEMOCRACY: THE STATE OF THE ART OF DEBATES IN FOUR KEY ISSUE AREAS}

The subsequent four chapters focus on four major issue areas of global governance. Besides providing a comprehensive review of the global governance literature in each domain, some of the chapters examine concrete cases of global governance, stretching across the entire governance spectrum from mostly state-directed cases (security and economic governance), to public-private arrangements (environmental governance), to predominantly private cases (business-directed governance in human rights issues). All in all, these case studies underpin the central thesis that global governance is a multifaceted phenomenon that, importantly, varies both across and within key areas of global politics. It is precisely the variety of global governance arrangements that demonstrates the need for a more thorough investigation into the different ways to democratize them.

Emilie Bécault, in Chapter 4, 'Democratizing global environmental governance? The case of transnational climate governance', examines the case of global environmental governance with a specific focus on hybrid transnational climate governance. She shows that if a consensus seems to be emerging on the superior relevance of deliberative theories of democracy for both assessing and enhancing the deliberative quality and ecological effectiveness of global climate politics, proponents of this model have yet to tell us how problems of representation and accountability can be resolved. This is especially the case in regard to voluntary-based governance initiatives whose actors often have no mandate to enforce participation and compliance. She suggests that democratizing global climate politics - and global environmental governance more generally - requires first and foremost a shift of attention away from questions of 
'procedural democratic legitimacy' toward the consideration of a system of governance that promotes favourable conditions of governance as nondomination. This, it will be shown, can best be realized (for now) through a 'polycentric' climate governance architecture that involves a plurality of relatively autonomous, formal or informal governing units operating at differing scales and levels, and whose interactions are jointly coordinated by a broader set of norms

In Chapter 5, 'Democratic global (economic) governance and the emergence of the G20', Sven Van Kerckhoven and Christophe Crombez present a political economic approach to democracy and global governance, with a particular focus on (global) public goods provision. The authors argue that global governance arrangements fulfil a certain number of functions in order to help countries to overcome the prisoner's dilemma hurting the provision of global public goods. In doing so, global governance arrangements can be welfare creating. However, the distribution of welfare gains resulting from the global governance arrangement is not necessarily fair or equal. The division of welfare creation is determined within the global governance arrangements and is hence dependent upon the voting shares and institutional configuration of the global governance mechanism at hand. For economic governance, the main global governance arrangements consist of international institutions, such as the International Monetary Fund (IMF), the World Bank and the World Trade Organization (WTO). The first two were set up in the aftermath of the Second World War and still strongly reflect the post-World War economic realities today. Consequently, the advanced economies are to a certain extent over-represented and dominate these institutions. In light of the recent changes in the global economic landscape, emerging economies are increasingly calling for a shift in voting shares. Due to the threat of these emerging economies, or out of self-interest of the advanced economies, global governance arrangements can democratize (in terms of representation), leading to different policy outcomes. This has been the case, for example, for the G20.

In Chapter 6, 'Global business and human rights governance: the case of corporate social responsibility', Stephanie Bijlmakers and Geert Van Calster examine the state of the art on how global governance and democracy have been conceptualized in the area of human rights. This chapter studies global business and human rights governance and focuses in particular on the case of corporate social responsibility (CSR). While being anchored in legal literature, it draws on political science and management scholarship to determine how CSR, as one variant of human rights governance, and its democratic legitimacy have been conceptualized in the literature. It points to the lack of appropriate legal anchors to appreciate CSR as global governance, as well as the role of enterprises in it, in legal 
terms. The chapter presents an agenda for future research to determine the potential and actual contribution of CSR to serve as a democratizing force within the overall global business and human rights governance landscape. It points to the need for comparative studies on the democratic quality of CSR decision-making procedures that give due account of the extent to which these procedures are embedded in a human rights framework. Also, greater attention to the substance of CSR norms is warranted, the argument holds, in order to shed light on how these affect corporate citizenship and power relations in what can be viewed as an emerging polycentric CSR regulatory regime. The ISO26000 standard serves as an illustrative case study.

Chapter 7, by Kenneth Chan and Jan Wouters on 'Enforcement in global security governance: navigating Great Power confabulation in the United Nations Security Council', challenges the commonly held belief that greater democratic structures and proceedings can always improve the efficacy of governance systems by investigating the most seminal example of high-level discretionary decision-making: United Nations Security Council (UNSC) enforcement determinations conducted under the Chapter VII mandate. The classic trade-off between broader and more inclusive participation in decisions to sanction the use of force, and the need to act discretely, efficiently and effectively, is brought into stark relief in the case of this high-level institution, whose unfettered powers and internal political divisions have effectively brought it to its knees - at least in the case of this most important function. The situation has only worsened in the last few years, as incidents such as China's stand-off in the South China Seas and Russia's increasingly emboldened acts of aggression against its neighbours have revived long-quieted Cold War tensions amongst Council members. Such events have heralded what some authors have described as a 'crisis of legitimacy', which many others assert can only be resolved with major Security Council reform. Yet, ideal or not, it is clear that such a position ignores the political and military inequalities between states that dictate the agenda of the contemporary landscape of peace and security. Thus, this demands compromise of the vision of reformists and sceptics.

Investigating various reform proposals of the institution, both democratic and not, the authors argue that key features of democratic reform are more ideal than others in the context of this debate. Calls for greater democratic participation, for example, tend to bury important debates relating to greater transparency and accountability. Indeed, as the authors submit, output legitimacy should be the primary concern to reformists. Consequently, two distinct legitimacy crises are highlighted at the institutional level. Firstly, a crisis arises because of the Council's frequent inability to surmount the political grievances of its veto-wielding permanent 
members in order to act in situations which objectively require their intervention; historically during the Rwandan genocide of 1994, but more recently during the Syrian civil war. Secondly, and perhaps most troubling, is the ability of its permanent members to leverage their all-powerful positions on the Council to act with impunity outside the UN system, engaging in aggressive acts whilst blocking the Council from action. In relation to the second problem in particular, the authors observe an important role for public international law specifically in taming Great Power belligerence. They suggest that the need of Great Powers to appear both legally (and consequently morally) right in their actions can be utilized by closing existing gaps (whether real or merely perceived) within the law which allow them to justify their actions as permissible. Finally, in response to these problems, the chapter highlights a number of strategies that have been developed over the years within the greater security governance framework, of which the UN and the UNSC are but merely one part, to circumnavigate deadlock. Though change must undoubtedly be brought to the Council if it hopes to overcome its marginalization, these strategies - which include the adoption of the 'Uniting for Peace' Resolution by the UN General Assembly, the UN Secretary-General's development of the peacekeeping paradigm many decades ago during the height of the Cold War, ongoing humanitarian intervention debates, and the increasingly autonomous role of regional security organizations - suggest a far more democratically robust system than one might initially assume.

\section{PART III: TRANSCENDING THE STATE OF THE ART OF RESEARCH ON GLOBAL GOVERNANCE AND DEMOCRACY}

In Part III, the volume provides a set of innovative proposals to advance research on global governance and democracy, both within and across the selected disciplines. To this effect, much attention is paid to the development of more informed dialogues between empirical and normative approaches.

In Chapter 8 on 'Global governance and the challenges of diversity', Colleen Carroll and Emilie Bécault develop a conceptual framework of global governance so as to better cope with the phenomenon's empirical diversity and complexity. They propose a conceptual approach that focuses on two dimensions of global governance: the micro- and the macro-dimensions. At the micro-level, namely at the level of the governing units, the framework addresses the following variables: agency, the decision-making norms, the decision-making processes and procedures, 
and policy instruments (formal rules and regulations, voluntary standards, market-based instruments). The macro-dimensions of global governance focus attention on the level of the population of global governance arrangements, and the framework of these dimensions focuses on issues related to the macro-structural normative foundations of global governance arrangements (constitutive norms), the structural distribution of authority in the overall governance system, and questions of scale or scope (local, transnational, trans-scalar or global). After describing each of these core elements of the conceptual framework, this chapter concludes with an examination of the implications of this conceptual framework for theorizing about democracy within a global governance context.

In Chapter 9 on 'Reconceptualizing the challenges for theories of democracy', Alessandro Mulieri, Antoon Braeckman and Tim Heysse advocate a context-sensitive and bottom-up approach to the democratization of global governance. Specifically, they focus on three key notions of democratic theory - legitimacy, representation and accountability - and assess their relevance for the general topic of global governance and democratic government. The authors argue in favour of a theoretical framework that merges together a productive idea of political representation and informal and horizontal notions of accountability. Since there is no demos that grounds global governance arrangements, the process of representation of global governance actors, they suggest, can be a good starting point to create and imagine constituencies of communities. Specifically, visibly staging conflict and debate through a set of representative practices can be a first crucial step to democratize global governance. If we think of democracy also as a mechanism that makes representatives visibly and publicly accountable, the idea of representation as community building must be complemented by mechanisms of accountability. Thus, the chapter refers to informal and horizontal notions of accountability as important instruments to correct the possible democratic drifts of representation. Enhancing the accountability standard of the demoi of global governance also enriches its legitimacy by bringing global governance closer to its agents and subjects.

\section{PART IV: SUMMARY AND CONCLUSIONS}

In the final part, a concluding chapter, 'Democratic legitimacy and global governance: a research agenda', written by the editors, takes stock of the major findings emerging from the preceding chapters. It re-emphasizes the need to rely on a variety of disciplinary and methodological approaches for achieving a more thorough understanding of global governance and 
its democratization, and concludes with a set of reflections on the importance of political visibility and innovative modes of representation for democratizing global governance, setting an agenda for future research and theorizing.

\section{REFERENCES}

Barnett, M. and Sikkink, K. (2008), 'From international relations to global society', in Reus-Smit, C. and Snidal, D. (eds), The Oxford Handbook Of International Relations, Vol. 5. Oxford Handbook Online, pp. 62-83, http:// dx.doi.org/10.1093/oxfordhb/9780199219322.001.0001.

Brassett, J., Richardson, B. and Smith, W. (2012), 'Private experiments in global governance: primary commodity roundtables and the politics of deliberation', International Theory, 4 (3), 367-399.

Commission on Global Governance (1995), Our Global Neighborhood: The Report of the Commission on Global Governance. New York: Oxford University Press.

Dingwerth, K. and Pattberg, P. (2006), 'Global governance as a perspective on world politics', Global Governance: A Review of Multilateralism and International Organizations, 12 (2), 185-203.

Finkelstein, L.S. (1995), 'What is global governance', Global Governance, 1, 367-372.

Kersbergen, K.V. and Waarden, F.V. (2004), "Governance” as a bridge between disciplines: cross-disciplinary inspiration regarding shifts in governance and problems of governability, accountability and legitimacy', European Journal of Political Research, 43 (2), 143-171.

Pauwelyn, J., Wessel, R.A. and Wouters, J. (2012), Informal International Lawmaking. Oxford: Oxford University Press.

Rosenau, J.N. and Czempiel, E.O. (eds) (1992), Governance Without Government: Order and Change in World Politics. Cambridge: Cambridge University Press.

Weiss, T.G. (2000), 'Governance, good governance and global governance: conceptual and actual challenges', Third World Quarterly, 21 (5), 795-814. 
Emilie Bécault, Matthias Lievens, Jan Wouters, and Antoon Braeckman - 9781781952627 Downloaded from PubFactory at $04 / 26 / 2023$ $09: 41: 59 \mathrm{AM}$ 